\title{
Arc flash fault detection in wind farm collection feeders based on current waveform analysis
}

\author{
Bin WANG ${ }^{1}$, Jiang $\mathrm{NI}^{\mathbf{1}}$, Jianzhao GENG ${ }^{\mathbf{1}}$, Yuanyuan $\mathbf{L U}^{\mathbf{1}}$, \\ Xinzhou DONG ${ }^{1}$
}

MPCE

\begin{abstract}
High impedance faults (HIFs) are easy to occur in collective feeders in wind farms and may cause the cascading of wind generators tripping. This kind of faults is difficult to be detected by traditional relay or fuse due to the limited fault current values and the situation is worse in wind farms. The mostly adopted HIF detection algorithms are based on the $3^{\text {rd }}$ harmonic characteristic of the fault zero-sequence currents, whereas these $3^{\text {rd }}$ harmonics are very easy to be polluted by wind power back-to-back converters. In response to this problem, the typical harmonic characteristic of HIF arc flash based on Mayr's arc model is first analyzed, and the typical fault waveforms of HIF in wind farm are presented. Then the performance of the harmonic based HIF detection algorithm is discussed, and a novel detection algorithm is proposed from the viewpoint of time domain, focusing on the convex and
\end{abstract}

CrossCheck date: 5 August 2016

Received: 6 July 2015 / Accepted: 5 August 2016/Published online: 16 November 2016

(C) The Author(s) 2016. This article is published with open access at Springerlink.com

$\square$ Bin WANG

binw_ee@mail.tsinghua.edu.cn

Jiang NI

nijiang93@163.com

Jianzhao GENG

gengjianzhao@126.com

Yuanyuan LU

lyythu@qq.com

Xinzhou DONG

xzdong@mail.tsinghua.edu.cn

1 State Key Laboratory of Power System, Department of Electrical Engineering, Tsinghua University, Beijing 100084 , China concave characteristic of zero-sequence current at zerocrossing points. A HIFs detection (HIFD) prototype implementing the proposed algorithm has been developed. The sensitivity and security of the algorithm are proved by field data and RTDS experiments.

Keywords Wind farm, High impedance fault, Arc flash, Zero-sequence current, Convex and concave characteristic

\section{Introduction}

High impedance faults (HIFs) tend to occur on collection feeders in neutral-point effectively grounded wind farms, which are difficult to be detected by traditional protection methods. The continuous fault current will result in serious consequences: high temperature of cable head caused by arc flash may lead to inter-phase or three-phase short and even large-scale wind generation systems tripping accidents; the insulation breakdown of overhead wires can result in personal electric shock accidents. HIFs are threatening the safety of wind farms.

Over the last decades, much attention has been paid to the study HIFs. Many fault features have been extracted and the highly recognized ones are: radiation behavior [1-3] and harmonic distortions in voltage and current [4-9]. Plenty of detection algorithms have been proposed and analyzed, including electromagnetic radiation based algorithms [3], harmonic based algorithms [4-14], wavelet based algorithms [15-17], instantaneous power based algorithms [18], and some intelligent detection algorithms $[19,20]$. Due to the obvious $3^{\text {rd }}$ harmonic characteristic of HIFs, the harmonic based algorithms are the most commonly adopted in industrial application.

A new numerical algorithm for the analysis of single line to ground arc faults is presented [21] and a genetic algorithm 
is proposed to estimate the fault-related wiring parameters such as intermittent arc location and average intermittent arc resistance [22]. However, in wind farms the harmonics can be easily polluted by those from wind power back-to-back converters. The harmonic based algorithms and the above algorithms often have poor performance in wind farms because the harmonic proportion of fault current is relatively lower. The harmonic based algorithms may have difficulty to detect HIFs in wind farms.

Therefore, the research for HIF detection algorithms in wind farms is very important and the efficient algorithm to detect HIFs under the influence of converters is needed.

\section{Modeling of wind generation systems and HIFs}

\subsection{Modeling of wind turbine and permanent magnet synchronous generator (PMSG) system}

The wind turbine and permanent magnet synchronous generator system model is shown in Fig. 1. It contains wind turbine, permanent magnet synchronous generator and back-to-back converter set up by pulse width modulation (PWM) rectifier and inverter.

The rectifier is controlled by maximum power point tracking (MPPT), while the inverter is set by grid-connection control strategy. For MPPT control strategy, the relationship between wind power coefficient $C_{\mathrm{p}}$, pitch angle $\theta$ and the tip speed ratio $\lambda$ is as

$$
\begin{aligned}
C_{\mathrm{p}}= & (0.44-0.0167 \theta) \sin \left(\frac{\pi(\lambda-2)}{13-0.3 \theta}\right) \\
& -0.00184(\lambda-2) \theta
\end{aligned}
$$

For grid-connection control strategy, current reference values are given in $d q 0$ coordinate in order to achieve active and reactive power decoupling: $d$-axis current reference value is given by DC voltage controller, feeding grid; meanwhile $q$-axis current reference value is given by the reactive power controller, generating capacitive or inductive active power. Inner current loop

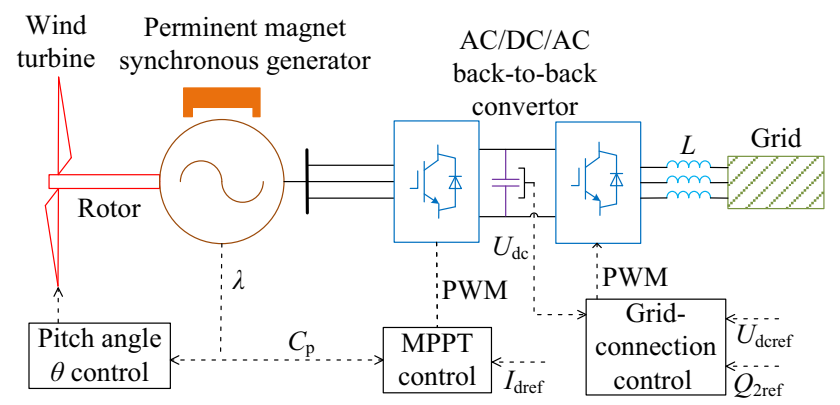

Fig. 1 Wind turbine and permanent magnet synchronous generator system is feedback control of $a b c$ phase current instantaneous values [23].

The steady-state voltage and current waveforms from single PMSG on $35 \mathrm{kV}$ feeder are shown in Fig. 3 where the PMSG starts to generate power from 0 to $5 \mathrm{~s}$. The lineto-line voltage is about $35 \mathrm{kV}$, active power produced by single wind turbine is $4.68 \mathrm{MW}$. As in Fig. 2 the output current is polluted by the converter and $3^{\text {rd }}$ harmonic distortion reaches at its worst $1.4 \%$ per turbine.

\subsection{Modeling of wind turbine and doubly-fed induction generator (DFIG) system}

The wind turbine and doubly-fed induction generator system model is shown in Fig. 3. The back-to-back converter is divided into two components: the rotor-side converter and the grid-side converter. The both sides' converters are voltage-sourced converters that use forcedcommutated power electronic devices (IGBTs) to synthesize an AC voltage from a DC voltage source. A capacitor connected on the DC side acts as the DC voltage source. A coupling inductor $L$ is used to connect grid-side converter to the grid. The three-phase rotor winding is connected to rotor-side converter by slip rings and brushes and the threephase stator winding is directly connected to the grid. The power captured by the wind turbine is converted into electrical power by the induction generator and it is transmitted to the grid by the stator and the rotor windings. The control system generates the pitch angle command and the voltage command signals $V_{\mathrm{r}}$ and $V_{\mathrm{gc}}$ for rotor-side and grid-side converter respectively in order to control the power of the wind turbine, the DC bus voltage and the reactive power or the voltage at the grid terminals [24].

\subsection{Modeling of high impedance faults}

Several classical models such as Mayr model [25], Cassie model [26] and cybernetic model are widely employed for HIFs arc simulations. Among these models,

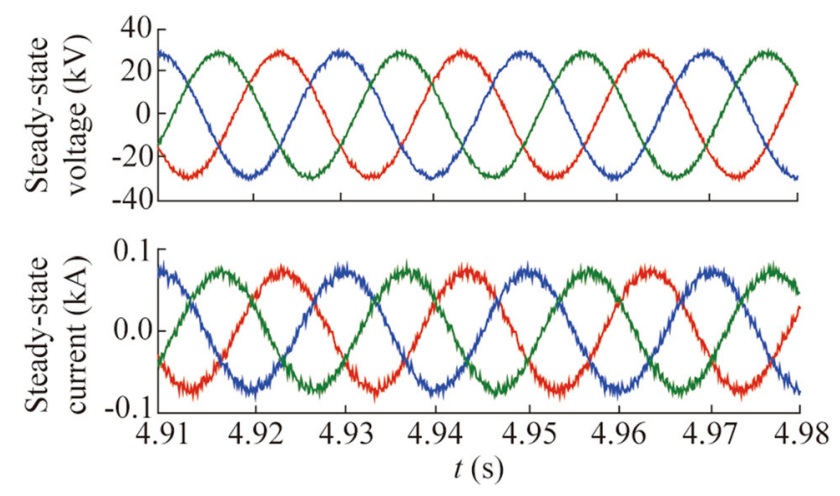

Fig. 2 Steady-state waveforms from single PMSG 


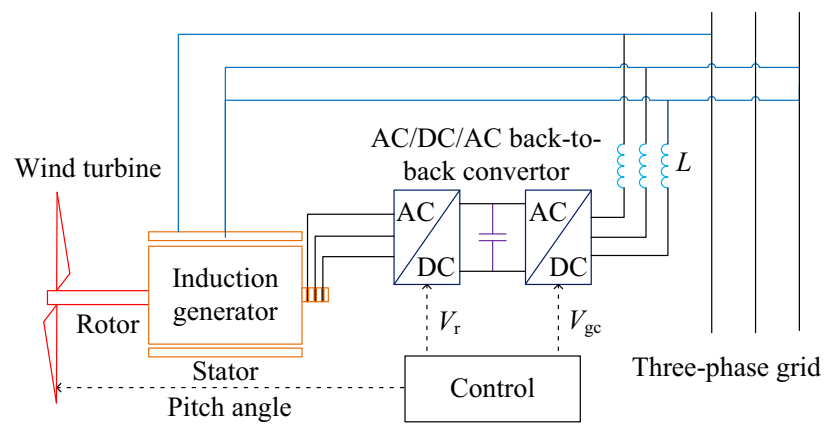

Fig. 3 Wind turbine and DFIG system

Mayr's equation is more suitable to simulate HIFs arc because of the limited fault current (usually under 100 A).

The Mayr equation is as

$$
(1 / g) \mathrm{d} g / \mathrm{d} t=\mathrm{d}(\ln g) / \mathrm{d} t=\left(1 / \tau_{m}\right)\left(E i / P_{m}-1\right)
$$

where $g$ is the arc conductance per length; $\tau_{m}$ is the temperature inertia constant of the $\operatorname{arc} ; P_{m}$ is the power loss constant of the arc per length; $E$ is the arc-path electric potential per length; $i$ is the arc current. In this thermal equation, if the power injection $E i$ is larger than the power dissipation constant $P_{m}$, the arc conductance will increase exponentially, otherwise decrease exponentially. For AC system, when arc current approaches zero in every cycle, $E i<P_{m}$, the conductance $g$ will decrease dramatically; after the current crossing zero, $E i>P_{m}, g$ will increase, thus resulting in a current distortion at each current zerocrossing point.

A Mayr arc model has been set up to simulate stable HIFs. The simulation result of zero-sequence current waveform is shown in Fig. 4 dotted line. An HIF laboratory test has been staged in Wroclaw University of Technology on an unloaded $10 \mathrm{kV}$ overhead feeder with different fault surfaces, including dry and damp pavement tiles, little damp sand, dry and damp gravel, dry and damp car tire. The solid line in Fig. 4 shows the zero-sequence current waveform with the fault surface of dry gravel. Although the magnitude of zero-sequence current varies from case to case, the waveforms present high similarity. The proposed Mayr model, therefore, is suitable to simulate HIFs.

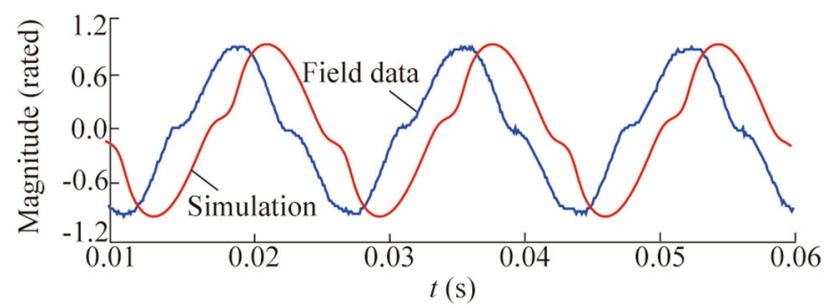

Fig. 4 Comparison of HIF currents between simulation and experiment
Table 1 Harmonics of currents with different fault surfaces

\begin{tabular}{llll}
\hline Type of fault soil & $\begin{array}{l}2^{\text {nd }} \text { harmonic } \\
(\%)\end{array}$ & $\begin{array}{l}3^{\text {rd }} \\
(\%)\end{array}$ & $\begin{array}{l}\text { THD } \\
(\%)\end{array}$ \\
\hline a) Pavement tiles (dry) & 1.7 & 3.3 & 5.3 \\
b) Pavement tiles (damp) & 1.7 & 4.2 & 5.7 \\
c) Gravel (dry) & 2.6 & 13 & 16 \\
d) Gravel (damp) & 1.4 & 13 & 15 \\
e) Car tire (dry) & 1.8 & 6.6 & 8.9 \\
f) Car tire (damp) & 1.2 & 7.7 & 9.3 \\
g) Sand (little damp) & 0.6 & 8.1 & 10 \\
\hline
\end{tabular}

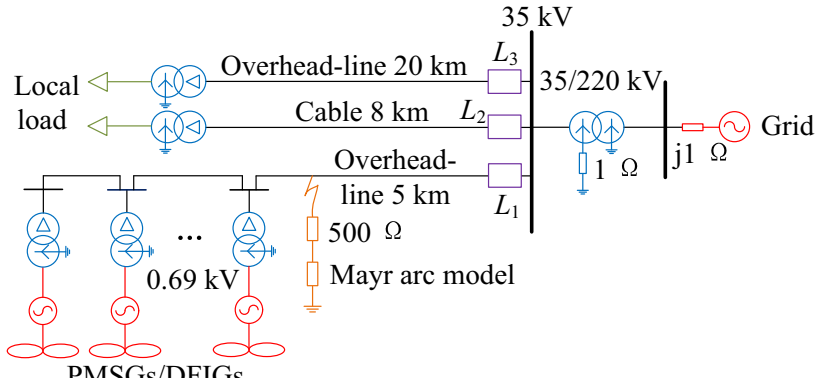

PMSGs/DFIGs

Fig. 5 Simulation circuit of HIF in wind farm

Harmonics analysis is employed on the HIF laboratory test waveforms with different fault surfaces, and the results are shown in Table 1.

The $2^{\text {nd }}$ and $3^{\text {rd }}$ harmonics and total harmonic distortion (THD) of zero-sequence current all vary in a wide range; hence it is difficult to set a definite threshold to balance the sensitivity and security of detection algorithms. For example, distortions of zero-sequence current waveforms of a) and b) are too slight to be detected by most spectrum based algorithms. Algorithms with lower threshold may have a relatively high sensitivity to detect the arcing fault; however, it could cause false alarm or tripping when harmonics distortion is polluted by wind power converters or noise.

\subsection{Simulation and analysis of HIFs in wind farm}

Large-scale wind farms generally connect to grid in centralized approach in China. The typical structure topology of effectively neutral grounded wind farm system with HIF is shown in Fig. 5 and the measuring point locates at the outlet of the collection line $L_{1}$. PMSGs and DFIGs both can be utilized to simulate wind generation system and the detailed parameters of the feeders are shown in Table 2.

Different HIFs with different fault locations can be simulated by changing position of Mayr arc model in Fig. 5 and it could be applied to different cases in wind farm. 
Table 2 Parameters of feeders

\begin{tabular}{lllll}
\hline Feeder & Parameters & $\begin{array}{l}\text { Resistance } \\
(\Omega / \mathrm{km})\end{array}$ & $\begin{array}{l}\text { Reactance } \\
(\Omega / \mathrm{km})\end{array}$ & $\begin{array}{l}\text { Capacitance } \\
(\mu \mathrm{S} / \mathrm{km})\end{array}$ \\
\hline $\begin{array}{c}\text { Overhead } \\
\text { line }\end{array}$ & $\begin{array}{c}\text { Positive- } \\
\text { sequence }\end{array}$ & 0.17 & 0.38 & 3.03 \\
& $\begin{array}{c}\text { Zero-sequence } \\
\text { Cable }\end{array}$ & 0.32 & 1.32 & 1.38 \\
& $\begin{array}{c}\text { Positive- } \\
\text { sequence }\end{array}$ & 0.30 & 0.26 & 60.56 \\
& Zero-sequence & 0.88 & 0.29 & 60.56 \\
\hline
\end{tabular}

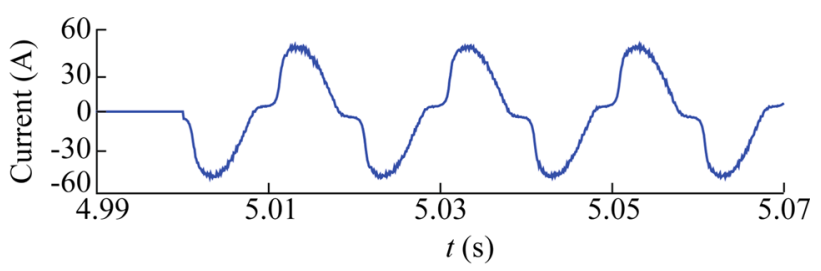

(a) Single wind generator

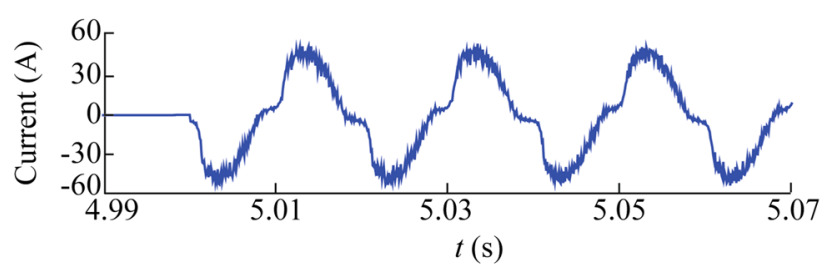

(b) 4 wind generators

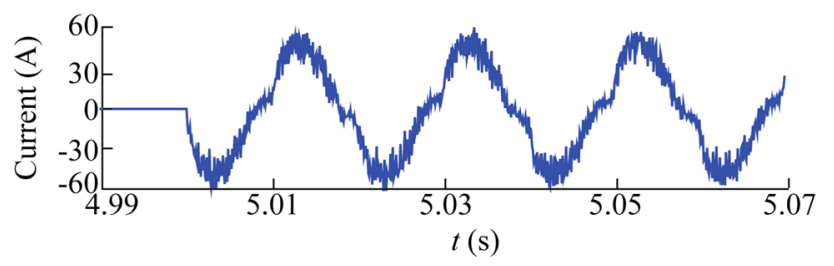

(c) 8 wind generators

Fig. 6 Fault zero-sequence current waveforms in wind farm

High impedance single phase fault occurs at $5.0 \mathrm{~s}$. The results in different cases with different fault locations are similar: parts of the simulated fault zero-sequence current waveforms in wind farm are shown in Fig. 6 and the harmonic analysis of fault zero-sequence currents is presented in Table 3.

The harmonic current outputted by wind power generation is random in magnitude and phase. Therefore, $3^{\text {rd }}$

Table 3 Harmonic analysis of fault zero-sequence current

\begin{tabular}{llll}
\hline $\begin{array}{l}\text { Number of wind } \\
\text { generators }\end{array}$ & $\begin{array}{l}1^{\text {st }} \text { harmonic } \\
\text { (A) }\end{array}$ & $\begin{array}{l}3^{\text {rd }} \text { harmonic } \\
(\mathrm{A})\end{array}$ & $\begin{array}{l}3^{\text {rd }} / 1^{\text {st }} \text { ratio } \\
(\%)\end{array}$ \\
\hline 0 & 48.3 & 9.9 & 20.5 \\
1 & 48.7 & 9.6 & 19.7 \\
2 & 49.4 & 9.4 & 19.1 \\
4 & 50.3 & 8.3 & 16.5 \\
8 & 52.8 & 5.9 & 11.2 \\
\hline
\end{tabular}

harmonic distortion should be analyzed considering the wind generators as a whole $3^{\text {rd }}$ harmonic resource. As shown in Table 3, with the number of wind generators increasing from 0 to $8,3^{\text {rd }}$ harmonic drops from 9.9 A to $5.9 \mathrm{~A}$ and the ratio between $3^{\text {rd }}$ and $1^{\text {st }}$ harmonic drops from $20.5 \%$ to $11.2 \%$.

Assuming that $1^{\text {st }}$ harmonic of collective feeders fault zero-sequence current is $I_{1}=A_{1} \sin \left(2 \pi f_{1} t\right)$ and the $3^{\text {rd }}$ harmonic produced by HIF model is $I_{3}=$ $A_{3} \sin \left(2 \pi f_{3} t+\Delta \varphi_{3}\right)$. The $3^{\text {rd }}$ harmonic injected into the fault circuit by wind generators is $I_{3}^{\prime}=A_{3}^{\prime}(n) \sin \left(2 \pi f_{3} t+\right.$ $\Delta \varphi_{3}^{\prime}$ ) ( $n$ is the number of wind generators).

The result is that with the number of wind generators increasing, the magnitude ratio between $3^{\text {rd }}$ harmonic and $1^{\text {st }}$ harmonic $\left|A_{3}-A_{3}^{\prime}(n)\right| / A_{1}$ may drop quickly because the wind generators injecting $3^{\text {rd }}$ harmonic magnitude $A_{3}^{\prime}(n)$ can rise. Therefore, it is difficult for harmonic based algorithms to set a definite threshold to detect HIFs in wind farms.

When high impedance ground faults occur, the magnitude ratio between $3^{\text {rd }}$ harmonic and $1^{\text {st }}$ harmonic is

ratio $=\frac{\sqrt{A_{3}^{2}+\left(A_{3}^{\prime}(n)\right)^{2}+2 A_{3} A_{3}^{\prime}(n) \cos \left(\Delta \varphi_{3}-\Delta \varphi_{3}^{\prime}\right)}}{A_{1}}$

Consider the worst thing that

$\cos \left(\Delta \varphi_{3}-\Delta \varphi_{3}^{\prime}\right)=-1$
ratio $=\frac{\left|A_{3}-A_{3}^{\prime}(n)\right|}{A_{1}}$

More simulations with different wind generators and feeder parameters have been carried on and the results all show that under the above Mayr and PMSG/DFIG model, large-scale wind generators connecting to grid has great impact on harmonic based algorithms: with the number of wind generators increasing, the magnitude ratio between $3^{\text {rd }}$ harmonic and $1^{\text {st }}$ harmonic can be lower than the general ratio and thus the performance of harmonic based HIF detection algorithms is poor. Therefore, the characteristic of HIFs should be studied to replace the harmonic feature and improve the detection algorithms.

\section{Fault characteristic extraction and detection algorithm}

\subsection{Convex and concave characteristic of zero- sequence current}

The HIF simulation results of the Mayr model is shown in Fig. 7, which presents the zero-sequence current 


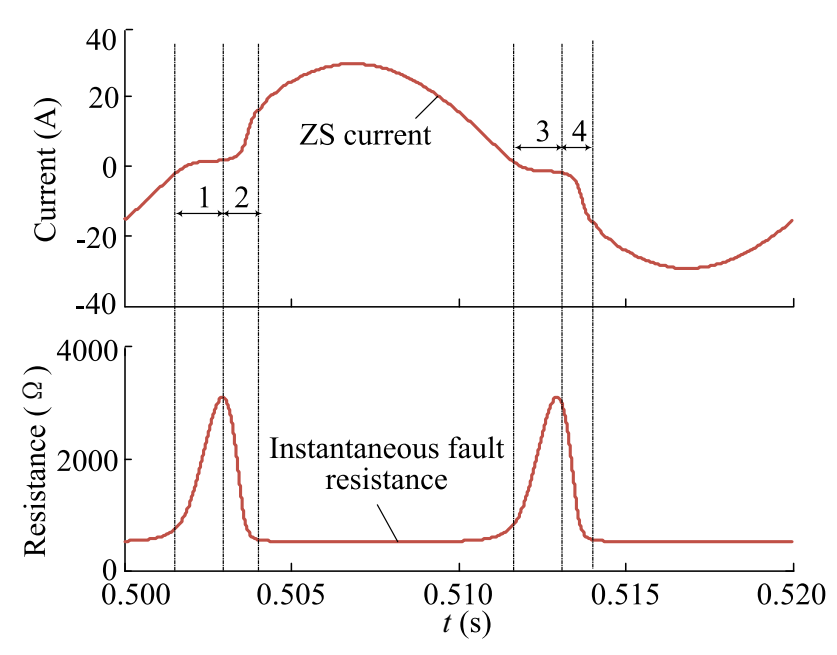

Fig. 7 HIF zero-sequence current and fault point resistance

waveform of the faulty feeder and the fault point resistance in details. Before the current zero-crossing point, the fault resistance increases sharply, resulting in a very small current value (Zones 1 and 3 in Fig. 7). After that, the current has a sudden increase due to the dramatic decrease of fault resistance (Zones 2 and 4 in Fig. 7).

This obvious feature can be described as convex and concave characteristic (CCC) of the zero-sequence current with the following definition.

\section{Definition:}

For an arbitrary twice differentiable function $f(t)$, if its second derivative $f^{\prime \prime}(t)$ is positive, namely

$f^{\prime \prime}(t)=\frac{\mathrm{d}^{2} f(t)}{\mathrm{d} t^{2}}>0$

where $f(t)$ is the concave characteristic at $t$. If $f^{\prime \prime}(t)$ is negative, namely

$f^{\prime \prime}(t)=\frac{\mathrm{d}^{2} f(t)}{\mathrm{d} t^{2}}<0$

where $f(t)$ is the convex characteristic at $t$.

The CCC present convex as shown in Zone 1 of Fig. 7 , then changes to be concave in Zone 2, after that, it turns to be convex again and lasts for a few milliseconds. The CCC of the negative half cycle is just opposite to the positive half cycle.

For a standard sine signal $f(t)=\sin (\omega t+\varphi)$ :

$f^{\prime \prime}(t)=-\omega^{2} \sin (\omega t+\varphi)$

If $f(t)$ is negative, $f^{\prime \prime}(t)$ would be positive, and the CCC of $f(t)$ is concave; otherwise, when $f(t)$ is positive, $f^{\prime \prime}(t)$ would be negative, and the CCC of $f(t)$ is convex.

Based on the unique CCC presented in the zero-sequence current, a novel detection algorithm is proposed in the following section.

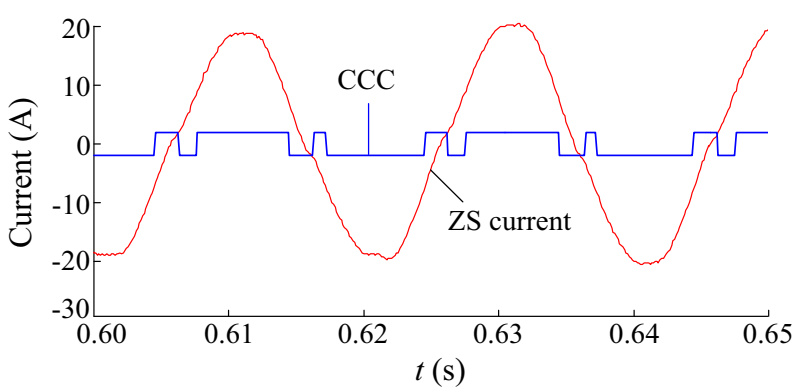

(a) Pavement tiles (dry)

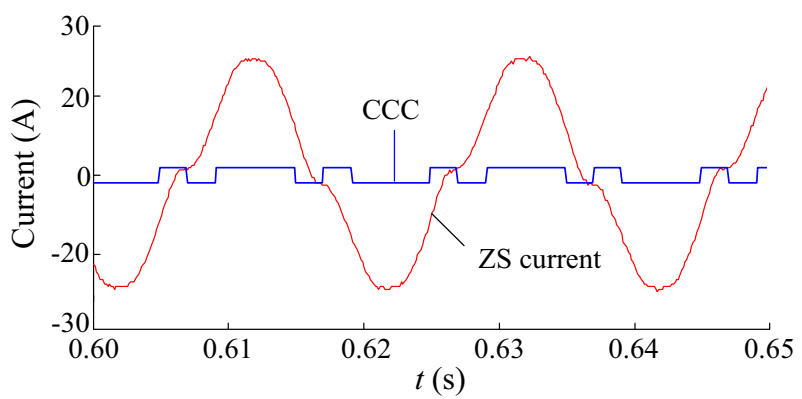

(b) Gravel (damp)

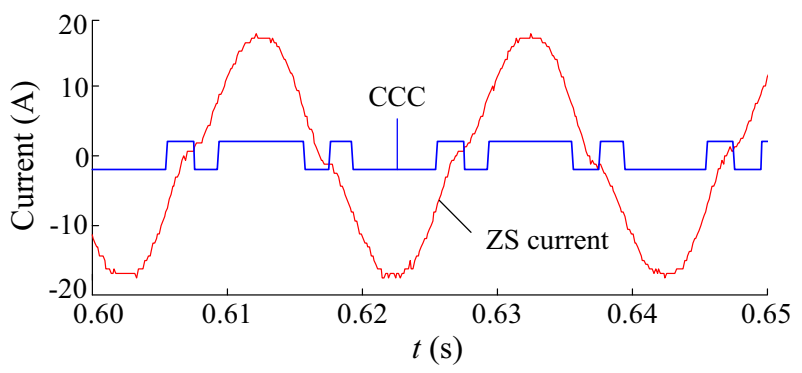

(c) Car tire (dry)

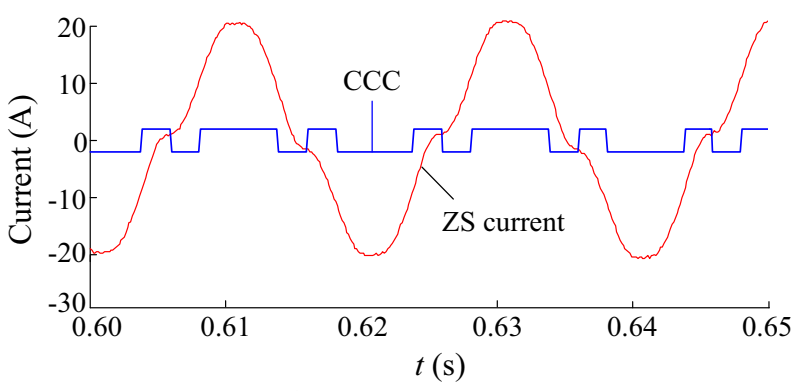

(d) Sand (little damp)

Fig. $8 \mathrm{HIFs}$ current waveforms and their CCC under different conditions

\subsection{Detection algorithm based on CCC of zero- sequence current}

The CCC based algorithm includes the following steps.

Step 1: Sample the real time zero-sequence current of each feeder, and then filter the data with a digital low pass filter, with a cut-off frequency of $500 \mathrm{~Hz}$. The linear phase 


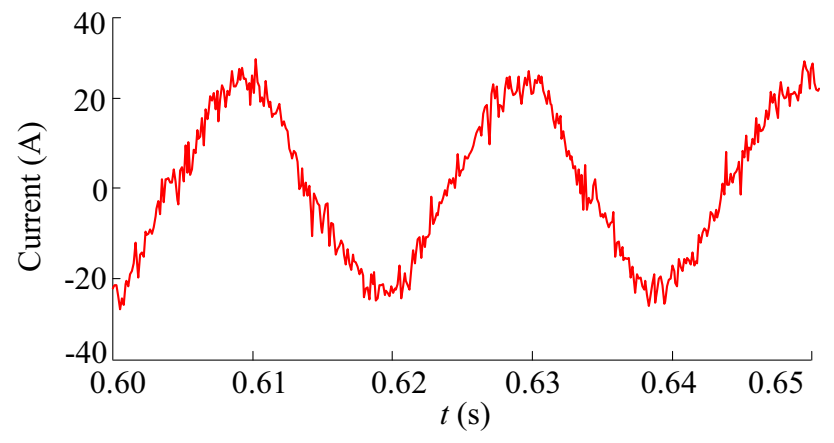

(a) HIF current with $15 \mathrm{~dB}$ white noise

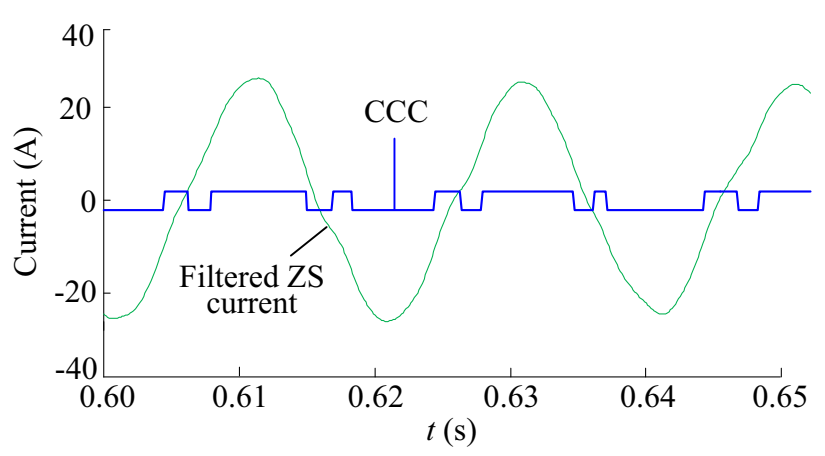

(b) Filtered current waveform and its CCC

Fig. $9 \mathrm{CCC}$ of HIF current with $15 \mathrm{~dB}$ white noise

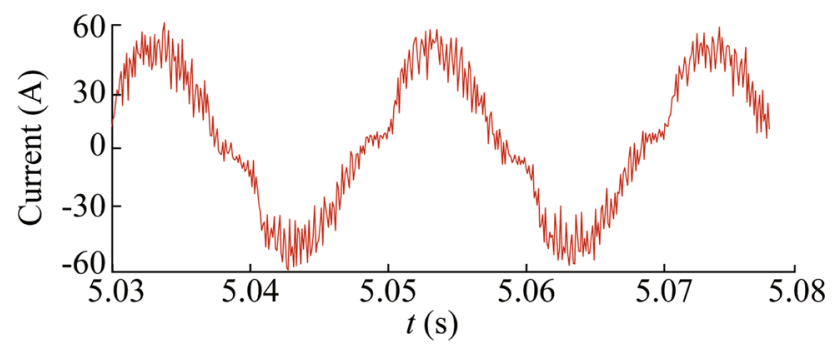

(a) HIF current in Fig.6(c)

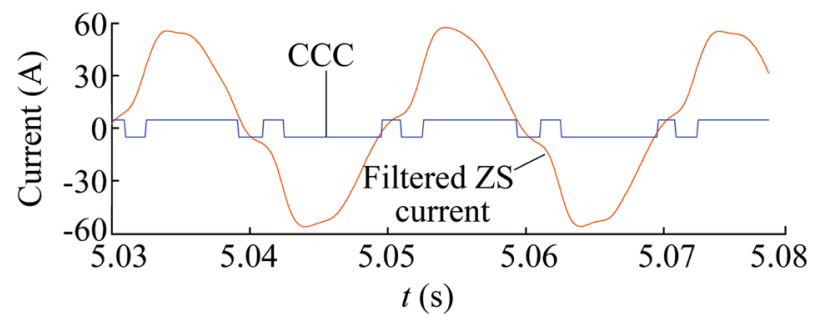

(b) Filtered current waveform and its $\mathrm{CCC}$

Fig. $10 \mathrm{CCC}$ of HIF current with 8 wind generators

filter should be used such as a Chebyshev filter. To avoid the edge effect of the convolution, a circular convolution is employed in filtering the data.

Step 2: Calculate the digital second derivative of the filtered zero-sequence current.

$i^{\prime \prime}(n)=i(n+1)-2 i(n)+i(n-1)$

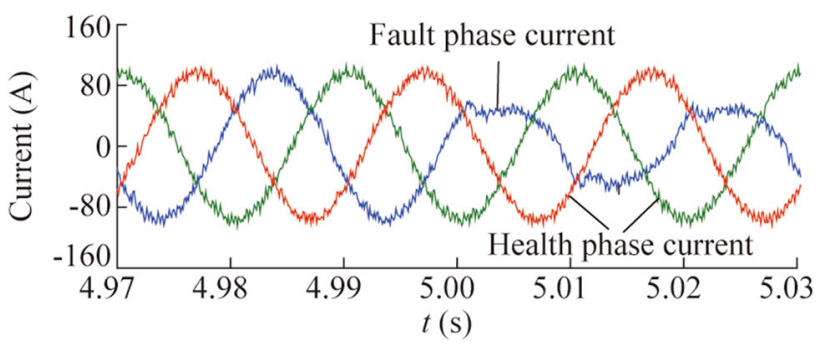

Fig. 11 HIF three phase current waveforms on collective feeders in wind farm

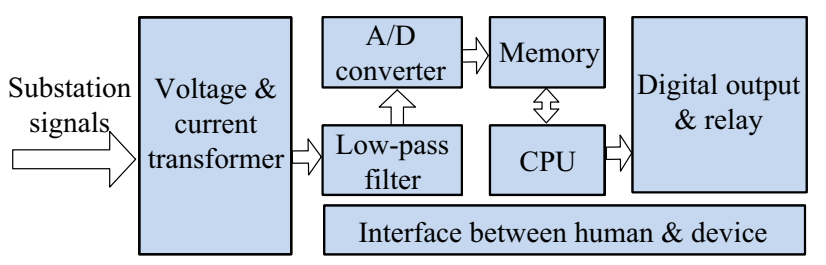

Fig. 12 System structure of the HIFD prototype

where $i^{\prime \prime}(n)$ is the digital second derivative; $i(n+1)$, $i(n)$ and $i(n-1)$ are next, current and previous filtered current samples respectively.

Step 3: Detect the suspected fault.

It is considered as a noise disturbance if the CCC changes more than eight times per cycle; it is considered as a suspected HIF when the filtered zero-sequence current waveform is convex at the positive zero-crossing nearby zone (current values increase from negative to positive), and then changes to be concave in the following 1/8 cycle;

It is also considered as a suspected HIF when the zerosequence current is concave at the negative zero-crossing nearby zone (current values change from positive to negative), and then changes to be convex in the following $1 / 8$ cycle.

Step 4: If the lasting time of the suspected HIF reaches the pre-determined setting time $T_{\text {set }}$, the occurrence of a HIF will be ensured. $T_{\text {set }}$ is preferred to be set in a range of 2 to 10 times period.

Note: In Step 1, the cut-off frequency of $500 \mathrm{~Hz}$ is chosen owing to the fact that low order harmonics, such as $2^{\text {nd }}$ harmonic and $3^{\text {rd }}$ harmonic are most evident in fault current [5-7]. A filter with such a cut-off frequency can eliminate noises and at the same time reserve the useful low order harmonics.

In Step 3, the noise disturbance criterion is set due to the fact that under HIFs circumstance, the CCC changes only six times per cycle.

\subsection{Sensitivity analysis of algorithm based on CCC}

Some types of the recorded zero-sequence (ZS) current waveforms fault soil are shown in Fig. 8 and the 


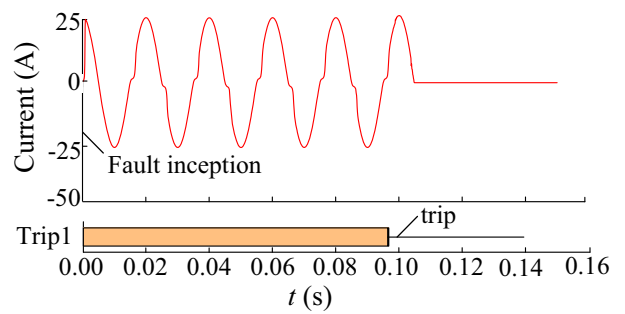

(a) ZS current and trip signal of feeder $L_{1}$ under fault surface condition 1

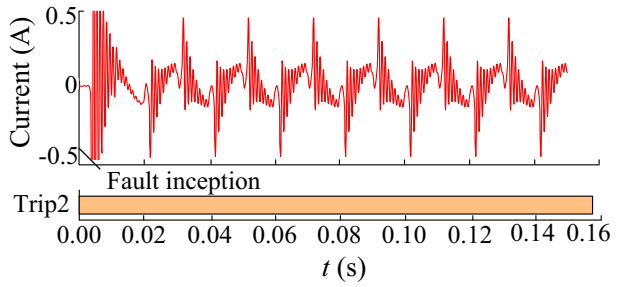

(b) ZS current and trip signal of feeder $L_{2}$ under fault surface condition 1

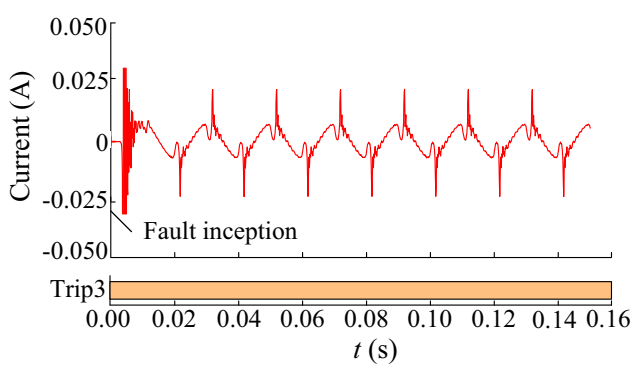

(c) ZS current and trip signal of feeder $L_{3}$ under fault surface condition 1

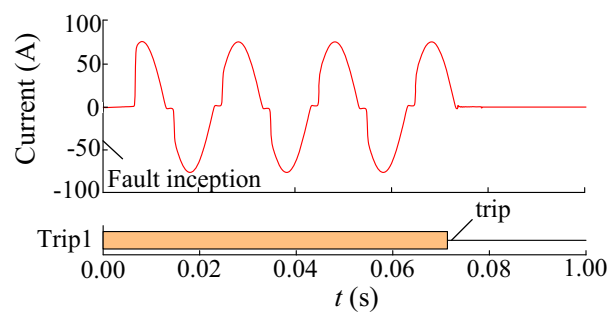

(d) ZS current and trip signal of feeder $L_{1}$ under fault surface condition 2

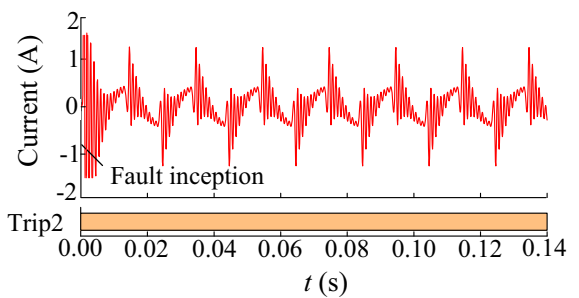

(e) ZS current and trip signal of feeder $L_{2}$ under fault surface condition 2

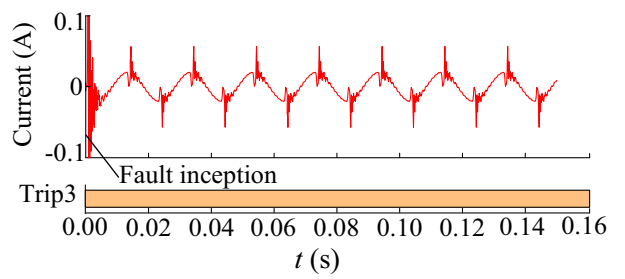

(f) ZS current and trip signal of feeder $L_{3}$ under fault surface condition 2

Fig. 13 Zero-sequence currents and trip signals generated by RTDS experiment corresponding $\mathrm{CCC}$ of each filtered waveform (positive value represents convex and negative value represents concave).

Obviously, the HIFs are all easy to be detected by CCC based algorithm in spite of the different current magnitudes and the real shapes of current waveforms.

In consideration of much harsher field condition, a white noise with intensity of $15 \mathrm{~dB}$ has been added to each current in Fig. 8. The proposed algorithm is also immune to this noise disturbance, and gives accurate detection results to all 7 cases. An example is shown in Fig. 9.

In addition, under the influence of wind power converters, the proposed algorithm also performs well. The simulated HIF zero-sequence current waveforms in wind farm from Fig. 6 all can be detected by CCC based algorithm despite the faint $3^{\text {rd }}$ harmonic characteristic. For example, the CCC of HIF current waveform with 8 wind generators connecting to grid is shown in Fig. 10, and the proposed algorithm also gives accurate detection results.

\subsection{Reliability analysis of algorithm based on CCC}

The detection sensitivity is definitely improved by CCC based on algorithm, but it cannot prevent incorrect tripping. For harmonic based algorithms, the problem also exists because the current is polluted by the converter and $3^{\text {rd }}$ harmonic distortion may turn out to be an incorrect tripping.

To solve this problem, the feature of arc flash fault is analyzed and the assistant criterion is presented below. The HIF three phase current waveforms on collective feeders in wind farm is shown in Fig. 11, and it shows that only the fault phase current change suddenly when arc flash fault occurs.

Through theoretical analysis and hundreds of simulations, the assistant criterion can be the sudden change of the magnitude or phase of one phase current. With this kind of assistant criterion, the reliability of harmonic based algorithms and CCC based on algorithm can be ensured.

\section{HIFD prototype and RTDS experiment}

A HIFD prototype has been developed implementing the proposed algorithm. The system structure is shown in Fig. 12.

A RTDS experiment is conducted to prove the sensitivity and security of the HIFD prototype. The test simulation circuit is the same as that in Fig. 5, in which $L_{1}$ is the faulty feeder, while $L_{2}$ and $L_{3}$ are healthy feeders. The equivalent primary CT ratio is $25 / 1$. The sampling rate is $2.4 \mathrm{kHz}$ and $T_{\text {set }}$ is $0.06 \mathrm{~s}$. The digital trip signal generated 
by the prototype is fed back to RTDS to make a close loop test. Eighteen cases were tested, including 6 different fault surface conditions, with 3 tests of 3 feeders in each fault surface condition. Each case was tested for at least 15 times. During all the tests, the prototype presents good performance: there is no unwanted trip on healthy feeders or on non-fault condition; the faulty feeder is tripped in all fault surface conditions, although in some minor fault cases the prototype's response time is much longer than $T_{\text {set }}$ (up to $0.2 \mathrm{~s}$ ). Parts of the generated zero-sequence current waveforms are shown in Fig. 13. The parameters of fault surface condition 1 are: arc length $10 \mathrm{~cm} ; \tau_{m}=0.30 \mathrm{~ms}$; $P_{m}=20000 \mathrm{~W} / \mathrm{m}$; serial resistance $300 \Omega$. The parameters of fault surface condition 2 are: arc length $20 \mathrm{~cm} ; \tau_{m}=$ $0.21 \mathrm{~ms} ; P_{m}=20000 \mathrm{~W} / \mathrm{m}$; serial resistance $100 \Omega$.

\section{Conclusion}

In wind farms, high impedance faults are difficult to be detected by harmonic based algorithms which are commonly adopted in industrial application. Large-scale wind generators connecting to grid has great impact on harmonic based algorithms: under the influence of convertors, the $3^{\text {rd }}$ harmonic proportion in wind farms can be relatively lower and thus the performance of harmonic based HIF detection algorithms is poor.

The distortion of feeder's zero-sequence current caused by dynamic arc is extracted and described as concave and convex characteristic and a novel and practical detection algorithm is proposed. HIFs field data and RTDS experiment data prove the high sensitivity and reliability of the proposed algorithm. The proposed algorithm uses only current signals to detect HIFs, and therefore it is applicable in neutral-point effectively grounded distribution systems where voltage signals are not always available.

Acknowledgment This work was supported in part by National Natural Science Foundation of China (No. 51120175001, No. 51477084), and in part by the Beijing Natural Science Foundation (No. 3152016).

Open Access This article is distributed under the terms of the Creative Commons Attribution 4.0 International License (http:// creativecommons.org/licenses/by/4.0/), which permits unrestricted use, distribution, and reproduction in any medium, provided you give appropriate credit to the original author(s) and the source, provide a link to the Creative Commons license, and indicate if changes were made.

\section{References}

[1] Kim CJ (2009) Electromagnetic radiation behavior of lowvoltage arcing fault. IEEE Trans Power Deliv 24(1):416-423
[2] Ble FZ, Lehtonen M, Sihvola A et al (2014) Power arcing source location using first peak of arrival of RF-signal. Int Rev Electr Eng 9(4):873-881

[3] Mukherjee A, Routray A, Samanta AK (2015) Method for online detection of arcing in low voltage distribution systems. IEEE Trans Power Deliv. doi:10.1109/TPWRD.2015. 2392385

[4] Tavares MC, Talaisys J, Camara A (2014) Voltage harmonic content of long artificially generated electrical arc in out-door experiment at $500 \mathrm{kV}$ towers. IEEE Trans Dielectr Electr Insul 21(3):1005-1014

[5] Terzija V, Preston G, Popov M et al (2011) New static "airarc" EMTP model of long arc in free air. IEEE Trans Power Deliv 26(3):1344-1353

[6] Sarlak M, Shahrtash SM (2013) High-impedance faulted branch identification using magnetic-field signature analysis. IEEE Trans Power Deliv 28(1):67-74

[7] Sarlak M, Shahrtash SM (2011) High impedance fault detection using combination of multi-layer perceptron neural networks based on multi-resolution morphological gradient features of current waveform. IET Gener Transm Distrib 5(5):588-595

[8] Jeerings DI, Linders JR (1990) Unique aspects of distribution system harmonics due to high impedance ground faults. IEEE Trans Power Deliv 5(2):1086-1094

[9] Zhou J, Ayhan B, Kwan C et al (2012) High-performance arcing-fault location in distribution networks. IEEE Trans Ind Appl 48(3):1107-1114

[10] Macedo JR, Resende JW, Bissochi CA et al (2015) Proposition of an interharmonic-based methodology for high-impedance fault detection in distribution systems. IET Gener Transm Distrib 9(16):2593-2601

[11] Michalik M, Rebizant W, Lukowicz M et al (2006) Highimpedance fault detection in distribution networks with use of wavelet-based algorithm. IEEE Trans Power Deliv 21(4):17931802

[12] Koziy K, Gou B, Aslakson J (2013) A low-cost power-quality meter with series arc-fault detection capability for smart grid. IEEE Trans Power Deliv 28(3):1584-1591

[13] Ghaderi A, Mohammadpour HA, Ginn HL et al (2014) Highimpedance fault detection in the distribution network using the time-frequency-based algorithm. IEEE Trans Power Deliv 30(3):1260-1268

[14] Milioudis AN, Andreou GT, Labridis DP (2012) Enhanced protection scheme for smart grids using power line communications techniques-part I: detection of high impedance fault occurrence. IEEE Trans Smart Grid 3(4):1621-1630

[15] Costa FB, Souza BA, Brito NSD et al (2015) Real-time detection of transients induced by high-impedance faults based on the boundary wavelet transform. IEEE Trans Ind Appl 51(6):53125323

[16] Wang Z, Balog RS (2015) Arc fault and flash signal analysis in DC distribution systems using wavelet transformation. IEEE Trans Smart Grid 6(4):1955-1963

[17] Lai TM, Snider LA, Lo E et al (2005) High-impedance fault detection using discrete wavelet transform and frequency range and RMS conversion. IEEE Trans Power Deliv 20(1):397-407

[18] Cui T, Dong XZ, Bo ZQ et al (2011) Hilbert-transform-based transient/intermittent earth fault detection in noneffectively grounded distribution systems. IEEE Trans Power Deliv 26(1):143-151

[19] Gautam S, Brahma SM (2013) Detection of high impedance fault in power distribution systems using mathematical morphology. IEEE Trans Power Syst 28(2):1226-1234

[20] Michalik M, Lukowicz M, Rebizant W et al (2008) New ANNbased algorithms for detecting HIFs in multigrounded MV networks. IEEE Trans Power Deliv 23(1):58-66 
[21] Terzija V, Preston G, Stanojevic V et al (2015) Synchronized measurements-based algorithm for short transmission line fault analysis. IEEE Trans Smart Grid 6(6):2639-2648

[22] Yaramasu A, Cao Y, Liu GJ et al (2015) Aircraft electric system intermittent arc fault detection and location. IEEE Trans Aerosp Electron Syst 51(1):40-51

[23] Jin YD, Song Q, Liu WH (2008) Modeling and analysis of direct-drive permanent magnet synchronous wind generation system. Hydropower Autom Dam Monit 32(5):47-51

[24] Pena R, Clare JC, Asher GM (1996) Doubly fed induction generator using back-to-back PWM converters and its application to variable-speed wind-energy generation. IEE Proc Electr Power Appl 143(3):231-241

[25] Mayr O (1943) Beiträge zur theorie des statischen und des dynamischen lichtbogens. Electr Eng 37(12):588-608

[26] Cassie AM (1939) Theorie nouvelle des arcs de rupture et de la rigidité des circuits. CIGRE Rep 102:588-608

Bin WANG obtained a B.Sc. degree in electrical engineering from Shandong University of Technology, China, in 1999, and Ph.D degree from Shandong University, China in 2005. From July 2005 to December 2010, he has been working as a post doctoral fellow and assistant researcher at Tsinghua University, China. He now serves as an Associate Professor at Tsinghua University. From December, 2013, he works as a visiting scholar in CURENT center, University of Tennessee, USA. His main research interests are power system protection, substation automation based on IEC 61850 and power quality.
Jiang NI is a M.Sc. candidate in the department of electrical engineering, Tsinghua University. His research interests include power system fault detection and protection technology.

Jianzhao GENG received the B.Sc. degree in electrical engineering from Huazhong University of Science and Technology, China, in 2011, and master degree from department of electrical engineering in Tsinghua University, China, in 2014.

Yuanyuan LU is a M.Sc. candidate in the Department of Electrical Engineering, Tsinghua University. Her research interests include electrical power system fault analysis and transmission line protection and location.

Xinzhou DONG received the B.Sc., M.Sc. and Ph.D degrees in electrical engineering from Xi' an Jiaotong University, China, in 1983, 1991 and 1996 respectively. He furthered his post-doctoral research at the Electrical Engineering Station of Tianjin University, Tianjin, China, from 1997 to 1998. Since February 1999, he has been working at Tsinghua University, Beijing, China, where he currently serves as a Professor and the Director of Research Center of Protection and Control between Tsinghua Univ. and AREVA Co. His research interests include protective relaying, fault location, and application of wavelet transforms in power systems. 